\title{
Velocity distribution measurements in a fishway like open channel by Laser Doppler Anemometry (LDA)
}

\author{
S.M.Sayeed-Bin-Asad ${ }^{1, a}$, T. S. Lundström ${ }^{1}$, A.G. Andersson ${ }^{1}$ and J. G. I. Hellström ${ }^{1}$ \\ ${ }^{1}$ Division of Fluid and Experimental Mechanics, Luleå University of Technology, SE-971 87 Luleå, Sweden
}

\begin{abstract}
Experiments in an open channel flume with placing a vertical half cylinder barrier have been performed in order to investigate how the upstream velocity profiles are affected by a barrier. An experimental technique using Laser Doppler Velocimetry (LDV) was adopted to measure these velocity distributions in the channel for four different discharge rates. Velocity profiles were measured very close to wall and at 25, 50 and $100 \mathrm{~mm}$ upstream of the cylinder wall. For comparing these profiles with well-known logarithmic velocity profiles, velocity profiles were also measured in smooth open channel flow for all same four discharge rates. The results indicate that regaining the logarithmic velocity profiles upstream of the half cylindrical barrier occurs at $100 \mathrm{~mm}$ upstream of the cylinder wall.
\end{abstract}

\section{Introduction}

The turbulent flow around vertical cylinders in open channel has been extensively studied for many years; flow around semi-circular cylinders however has not been the subject of as many studies. One application for this type of structure is in fish migration where fishes swimming in the bow wake in front of the half cylinder used less energy to maintain their position in the flow [1]. It is then necessary to know how far the bow wake exists in front of the half cylinder and this can be identified measuring velocity profiles in different upstream region of the half cylinder. The area of bow wake ends where the velocity profile follows logarithmic law.

However, velocity distribution at or around any obstruction is one of important issues to obtain information of vortices. Different types of obstructions or barriers are installed in fish-ways to make proper passages to migrate fishes according to the situation. There are also some other application of open channel flow, such as, natural drainage systems in various creeks and rivers, rainwater in the channel of houses, flow in natural and human made canals, ditches of drainage, sewers, and gutters along roads, flow of small rivulets, and sheets of water across fields or parking lots and flow in the chutes of numerous water rides.

Many studies on open-channel phenomena have been performed since the 1970's [2-8]. Haro, A., et al. (2004) [9] studied the performance of swimming for upstream migrating fishes in open-channel flow for predicting passage through velocity barriers. They defined performance of upstream migrating fishes swimming through velocity barriers in a novel way and at a realistic scale in their study. Steffler, P. M. et al [10] conducted
Laser Doppler Anemometry (LDA) measurements to measure mean velocity and turbulence for uniform subcritical flow in an open channel. The results indicated that mean velocity profiles follow logarithmic law. Ardiçhoğlu and Kirkgöz (1997) [11] conducted an experimental study on the progression of the flow starting from developing toward fully developed flow using LDA. They found that the extension of boundary layer occurs at fully developed turbulent flow axis for a certain aspect ratio. Madad, Reza, et al (2015) [12] conducted both experimental and numerical investigation for fully developed laminar and turbulent channel flow using an air-water interface. They noted that the higher energy is transferred to the water than the energy is transferred to a solid wall in moving condition. Balachandar and Patel (2002) [13] found that for a smooth surface, the logarithmic law (figure 1 is a typical velocity profile) is followed by the measured mean velocity profiles and for a rough surface, a suitable downward shifting occurs. Tachie et al. (2003) [14] measured velocities on two types of rough surfaces (different geometry) and a smooth surface in a channel and they found that the roughness effects on the velocity field were similar as found in turbulent boundary layer for a gradient of zeropressure, although free surface influences the boundary layer in an open channel flow. They additionally found that wake parameters increased due to roughness of the surface as compared with a smooth surface. Afzal et al. (2009) [15] studied open-channel flows to find the effect of Reynolds number on the velocity distribution and they found that there is some extension of overlap with the log region which is affected by the variation of Reynolds number. However, Ghoma, Hussin [16] studied twophase flows both experimentally and numerically in an

\footnotetext{
${ }^{\mathrm{a}}$ Corresponding author: sayeed.asad@1tu.se
} 
open channel flow and they observed the reasonable stream-wise velocity profiles distribution in the channel. They also found the reasonable agreement in the results between the numerical and the experimental studies.

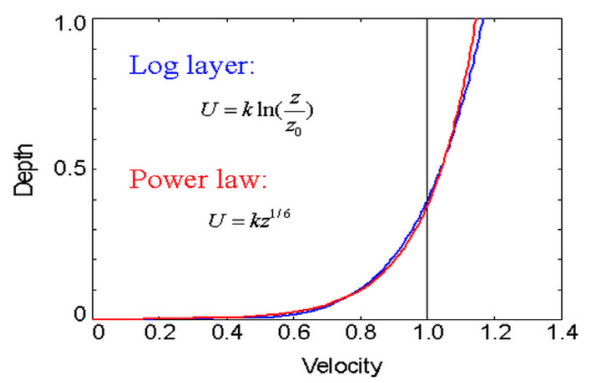

Figure 1. Typical logarithmic law and Power Law velocity profile, where $\mathrm{U}=$ Velocity ; $\mathrm{k}=$ Von Karman constant and $\mathrm{z}=$ Depth of water [17].

Laser Doppler velocimetry (LDV) is a well-proven non-invasive technique which accurately measures velocity of fluid flow at a point. An intersection of two laser beams is employed for this type of velocity measurement at a point. When a particle passes through the desired measuring point which is defined as probe volume, then the particle scatters light from the beams into a detector. The frequency of the resulted Doppler burst signal is directly proportional to the velocity of particle. Basic principle of a back scattering onecomponent LDA System (Dantec Dynamics) is shown in the figure 2. Velocity distribution in a channel flow can be accurately measured using the LDV which is, also known as LDA which measures the velocity of fluid based on the random sampling of individual velocity events which occur when particles pass through the measuring volume. Yeh and Cummins [18] first introduced LDA back in 1964, and since then it has been used broadly in experimental investigations of various fluid flow. LDA has been developed in the last 50 years as an enormously useful research instrument in the fluid dynamics area. Employing this LDA, accurate measurements all over the whole flow area can be obtained [19].

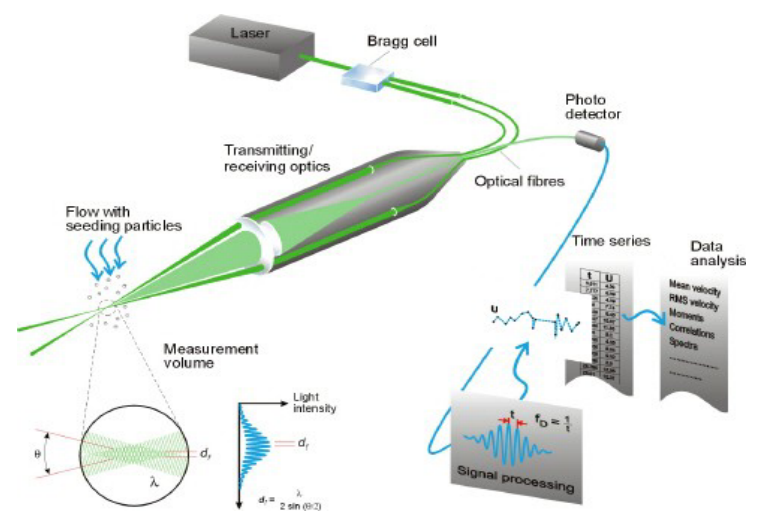

Figure 2. LDA principle [20].

A limited number of researchers have used the LDA technique for studying flow velocities in open channels. In the current study, the vertical velocity profiles in an open water channel with rectangular cross-section were experimentally investigated using the LDV technique for four different flow rates. The main focus is to investigate how steam-wise mean and RMS velocity profiles are varying in front of a half cylinder.

\section{Experimental facility and method}

The laboratory experimental investigations were carried out in a 7.5 meter long rectangular water flume with a cross-section of $295 \mathrm{~mm} \times 310 \mathrm{~mm}$ shown in the Figure 3. A half cylindrical barrier (D-shaped) as Liao, Beal [21] used their study was used in the experiment. The length and diameter of this D-shaped half-cylinder are $390 \mathrm{~mm}$ and $100 \mathrm{~mm}$ respectively. Velocity distributions were measured vertically at four different upstream regions of this D-shaped cylinder for a constant water depth $\left(\mathrm{D}_{\mathrm{w}}\right)$ of $180 \mathrm{~mm}$ (Height of the channel, $H=D_{w^{+}} D_{e}$ ) for four various flow discharge rates. An adjustable vertical gate was placed at the downstream end of the flume and a railmounted point gauges was installed on the top of the flume to control and measure the water depth in the channel. The sidewalls of the water flume were made of transparent $1.7 \mathrm{~mm}$ window glass to make possible velocity measurements using an LDA. A pump was used to re-circulate the water in the channel. A Danfoss MassFlo Coriolis flow meter (error $< \pm 0.5 \%$ ) [22] was employed to control the discharge rate.

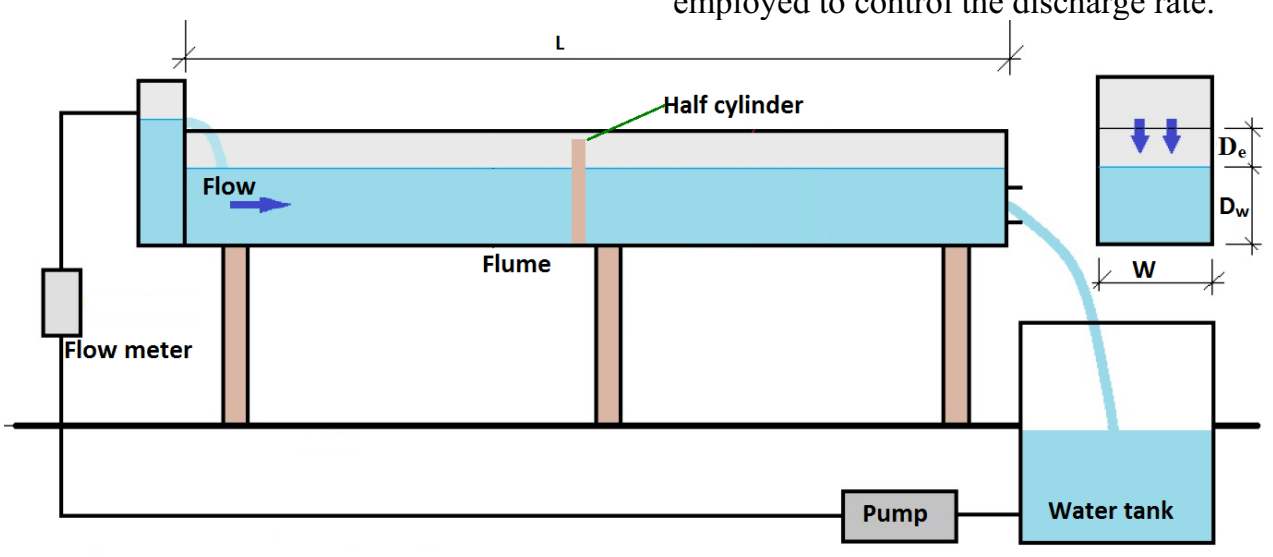

Figure 3. Schematic of the open channel flume 
A one-component Power Sight Solid State Laserbased LDV system (TSI Inc.) was used to measure the velocity profiles. The LDV measuring system consists of a $500 \mathrm{~mW}$ laser, transmitting optics, a fiber probe equipped with a $350 \mathrm{~mm}$ focal length lens, a photodetector, a signal processor and a computer. Installing half cylinder at middle of the channel, velocities at four different regions upstream of the cylinder such as close to cylinder wall, $25 \mathrm{~mm}, 50 \mathrm{~mm}$ and $100 \mathrm{~mm}$ ahead of the cylinder were measured for flow rate (Q)of 7650 liter/hour using 19 vertical points from channel bed to water surface. In the same way, velocities for 15000 , 20000 and 25000 liter/min discharge rates were measured. However, similar steps of measurement were adopted for measuring velocities at only one region without installing cylinder (empty channel with water flow only) for each discharge rate. Table 1 shows the detail condition of these experiments.

Table 1. Experimental conditions

\begin{tabular}{|c|c|}
\hline $\begin{array}{c}\text { Discharge, } \\
(\mathbf{l} / \mathbf{h})\end{array}$ & $\begin{array}{c}\text { Velocity distribution in the water } \\
\text { flume }\end{array}$ \\
\hline \multirow{2}{*}{7650} & Installing D-shaped cylinder $(\mathrm{a})$ \\
\cline { 2 - 2 } & No D-shaped cylinder installed $\left(\mathrm{a}_{0}\right)$ \\
\hline \multirow{2}{*}{15000} & Installing D-shaped cylinder $(\mathrm{b})$ \\
\cline { 2 - 2 } & No D-shaped cylinder installed $\left(\mathrm{b}_{0}\right)$ \\
\hline \multirow{2}{*}{20000} & Installing D-shaped cylinder $(\mathrm{c})$ \\
\cline { 2 - 2 } & No D-shaped cylinder installed $\left(\mathrm{c}_{0}\right)$ \\
\hline \multirow{2}{*}{25000} & Installing D-shaped cylinder $(\mathrm{d})$ \\
\cline { 2 - 2 } & No D-shaped cylinder installed $\left(\mathrm{d}_{0}\right)$ \\
\hline
\end{tabular}

\section{Results and discussion}

\subsection{Velocity Profiles}

The comparison of stream-wise component of the mean velocity profiles in an open channel for different discharges is shown in figure 4. It is obvious that the velocity profiles in figure 4 are following logarithmic law for channel flow as comparing with the typical velocity profiles (figure 1).

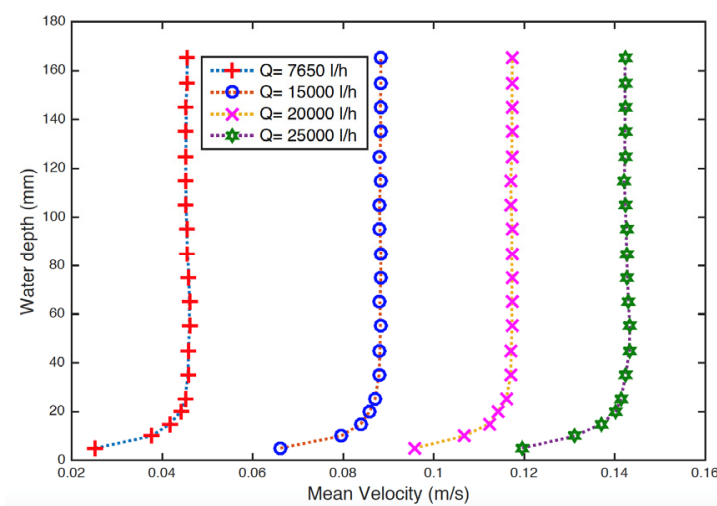

Figure 4. Velocity profiles for an open channel flow
Similarly, figure 5 depicts Root Mean Square (RMS) velocity or turbulent fluctuating velocity profiles for four flow discharge rates. All these profiles are comparable with profiles measured upstream of an installed half cylinder in the open channel.

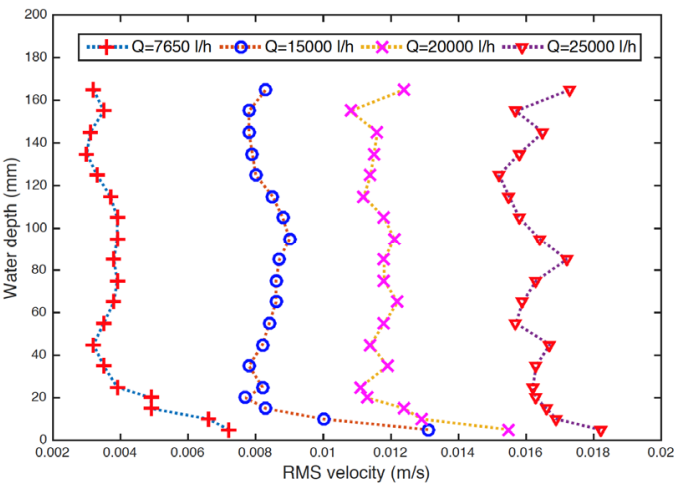

Figure 5. RMS velocity for an open channel flow

Figure $6 a$ depicts that mean stream-wise velocity profiles for flow both installing a half cylinder (four regions; close to wall, 25, 50 and $100 \mathrm{~mm}$ ahead of the cylinder) and with without installing a half cylinder (only open channel flow) for discharge rate (Q)of $7650 \mathrm{l} / \mathrm{h}$. Similarly, figure $6 b, 6 c$ and $6 d$ depict the mean velocity profiles for discharge rates 15000, 20000 and $25000 \mathrm{l} / \mathrm{h}$ respectively. In the same way, figure $7(a-d)$ show the Root Mean Square (RMS) velocity profiles for above mentioned all discharge rates. It is seen from figures 6 (ad) that velocity profile is greatly affected at close to the cylinder wall.

For the case of close to wall $(1 \mathrm{~mm}$ upstream of the wall), velocities close to the channel bed are low for all four discharge rates when the half cylinder is installed, while these velocities gradually increased as depth of water increased. This affect is gradually decreased as the distance from the cylinder wall is increased. Velocity profiles measured for all discharge rates are close to logarithmic profiles at $100 \mathrm{~mm}$ in front of the cylinder.

It is also found that velocities start increasing gradually for the case of close to wall $(1 \mathrm{~mm}$ upstream of the wall) as height of water from channel bed increased and the maximum velocities are found close to water surface using a half cylinder installed in the channel but when no cylinder is installed (empty channel), velocities gradually increase up to water height of around $40 \mathrm{~mm}$ then these velocities keep almost constant up to water surface for all measured discharge rates.

Turbulent fluctuating or the Root Mean Square (RMS) velocity distribution for all four discharge rates are shown in figure 7 where it indicates that velocity fluctuation starts slowing down from channel bed to around $20 \mathrm{~mm}$ height of water for the case of close to wall but after that, the fluctuation starts rising rapidly. However, for other cases like 25, 50 and $100 \mathrm{~mm}$ away from wall as well as empty channel flow, maximum fluctuation occurred at channel bed which gradually 


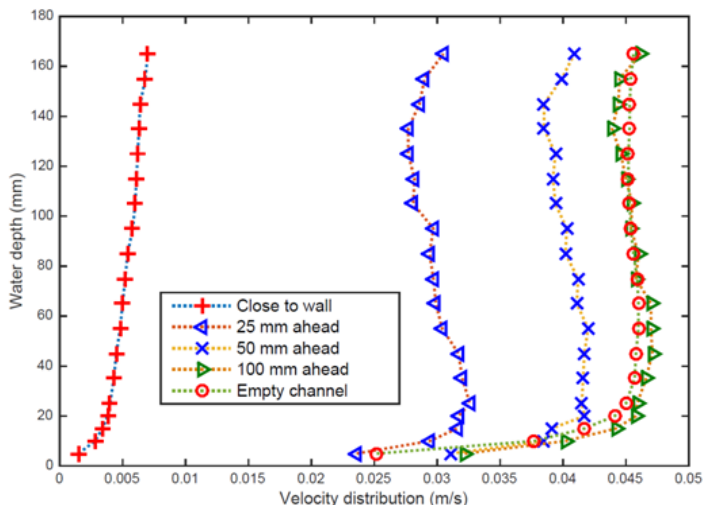

(a)

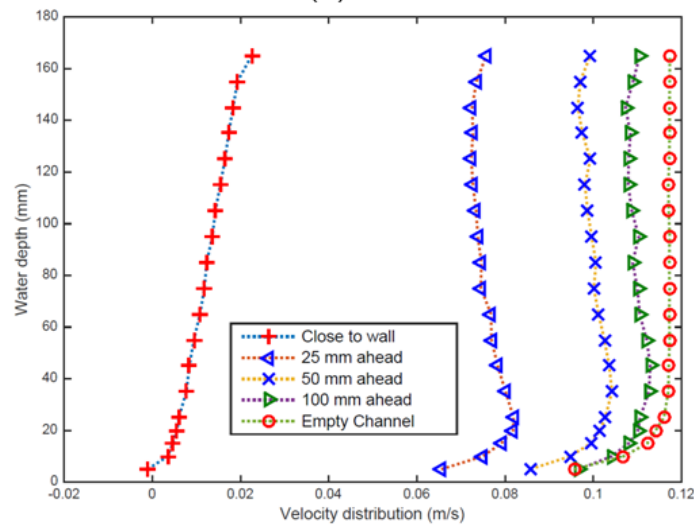

(c)

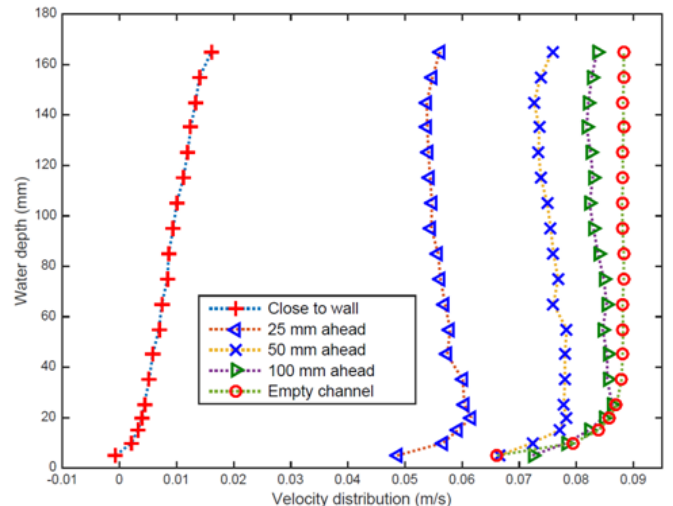

(b)

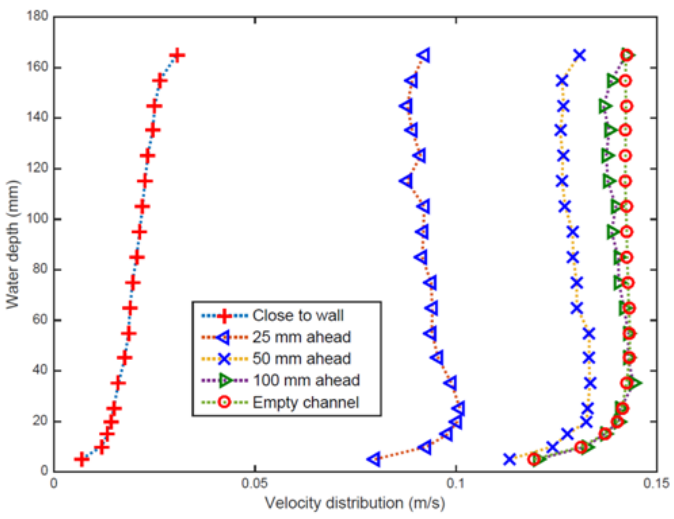

(d)

Figure 6. Velocity profiles for (a) $Q=7650$ l/h; (b) $Q=15000$ l/h; (c) $Q=20000$ l/h \& (d) Q=25000 l/h

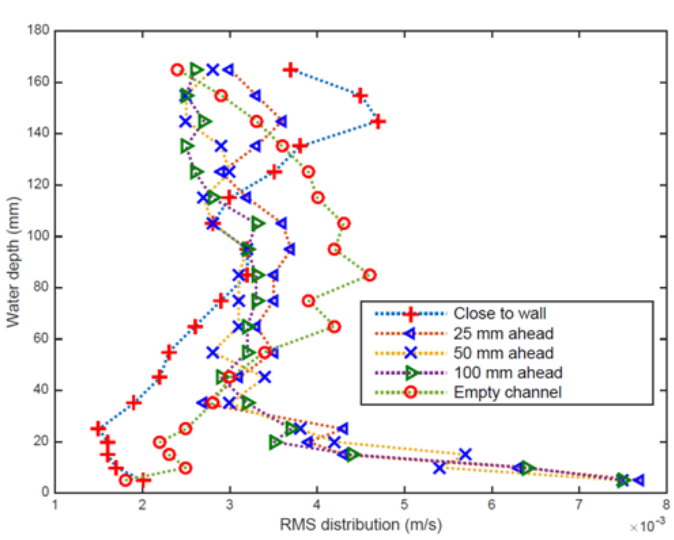

(a)

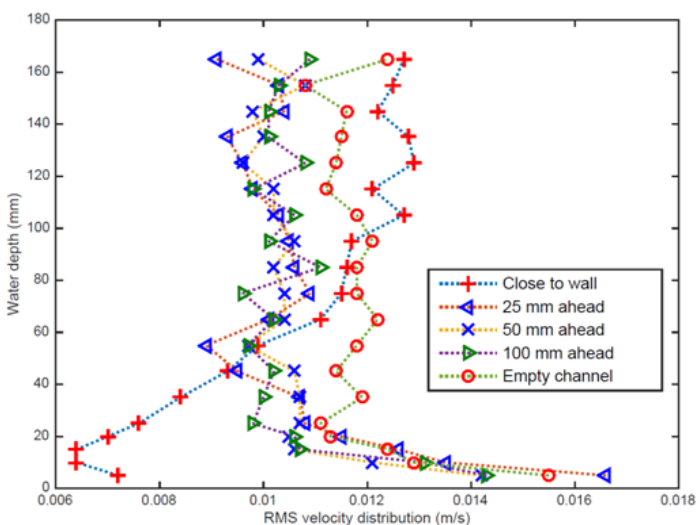

(c)

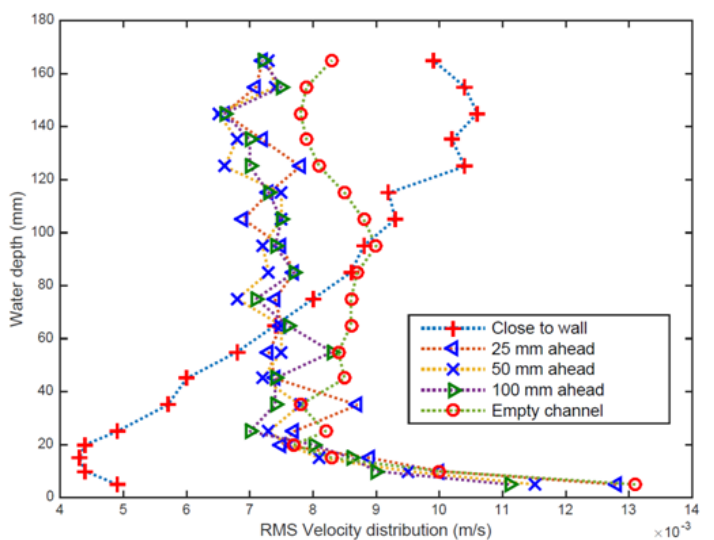

(b)

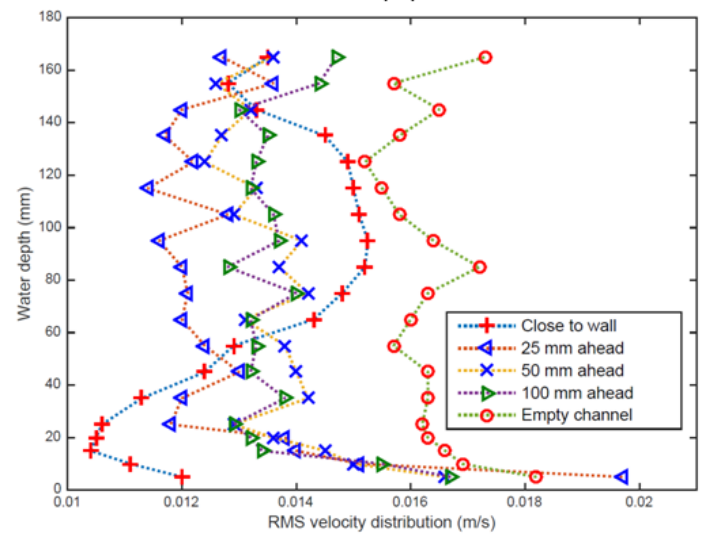

(d)

Figure 7. RMS Velocity profiles for (a) $Q=7650 \mathrm{l} / \mathrm{h}$; (b) $\mathrm{Q}=15000 \mathrm{l} / \mathrm{h}$; (c) $\mathrm{Q}=20000 \mathrm{l} / \mathrm{h}$ \& (c) $\mathrm{Q}=25000 \mathrm{l} /$ 
decreased up to $20 \mathrm{~mm}$ depth of water then the fluctuation started rising and dropping in zigzag way up to the water surface. The fluctuating velocities for almost all cases reach at roughly same value at approximately middle of water height but as discharge rate increases the deference between fluctuating velocities becomes larger, as it can be seen in the figure $7 \mathrm{~d}$ for maximum discharge rate $(\mathrm{Q}=25000 \mathrm{l} / \mathrm{h})$, $\mathrm{RMS}$ velocities do not reach at same point.

\section{Conclusion}

Velocity profiles were measured using LDV technique for four various discharge rates both installing a halfcylinder and without installing any half-cylinder in an open channel. Velocities at four different regions ahead of the cylinder were measured to examine the effect of the barrier on regaining logarithmic velocity profiles. The streamwise velocity profiles are regaining logarithmic velocity profiles at a distance of $100 \mathrm{~mm} \mathrm{(} \mathrm{1} \mathrm{diameter)}$ upstream of the half cylinder for all four discharge rates which indicate that the bow wake exists up to $100 \mathrm{~mm}$ upstream of the half cylindrical obstruction. However, Maximum turbulent fluctuation has also been observed near the channel bed for most discharge rates.

\section{Acknowledgement}

This work has been funded by the collaboration initiative StandUp for Energy. The research program is a part of the Swedish governments commitment to high quality research in areas of strategic importance.

\section{References}

1. Liao, J.C., A review of fish swimming mechanics and behaviour in altered flows. Philosophical Transactions of the Royal Society B: Biological Sciences, 2007. 362(1487): p. 1973-1993.

2. Nezu, I. and W. Rodi, Open-channel flow measurements with a laser Doppler anemometer. Journal of Hydraulic Engineering, 1986. 112(5): p. 335-355.

3. Nezu, I., Turbulence in open-channel flows. 1993.

4. Kang, S., X. Yang, and F. Sotiropoulos, On the onset of wake meandering for an axial flow turbine in a turbulent open channel flow. Journal of Fluid Mechanics, 2014. 744: p. 376-403.

5. Fischer, H.B., Longitudinal dispersion and turbulent mixing in open-channel flow. Annual Review of Fluid Mechanics, 1973. 5(1): p. 59-78.

6. Yen, B.C., Open channel flow resistance. Journal of Hydraulic Engineering, 2002. 128(1): p. 20-39.

7. Muste, M. and V. Patel, Velocity profiles for particles and liquid in open-channel flow with suspended sediment. Journal of hydraulic engineering, 1997. 123(9): p. 742-751.

8. Kirkgöz, M.S., Turbulent velocity profiles for smooth and rough open channel flow. Journal of Hydraulic Engineering, 1989. 115(11): p. 1543-1561.
9. Haro, A., et al., Swimming performance of upstream migrant fishes in open-channel flow: a new approach to predicting passage through velocity barriers. Canadian Journal of Fisheries and Aquatic Sciences, 2004. 61(9): p. 1590-1601.

10. Steffler, P.M., N. Rajaratnam, and A.W. Peterson, LDA measurements in open channel. Journal of Hydraulic Engineering, 1985. 111(1): p. 119-130.

11. Kirkgöz, M.S. and M. Ardiclioglu, Velocity profiles of developing and developed open channel flow. Journal of Hydraulic Engineering, 1997. 123(12): p. 10991105 .

12. Madad, R., et al., An investigation of channel flow with a smooth air-water interface. Experiments in Fluids, 2015. 56(6): p. 1-11.

13. Balachandar, R. and V. Patel, Rough wall boundary layer on plates in open channels. Journal of Hydraulic Engineering, 2002. 128(10): p. 947-951.

14. Tachie, M., D. Bergstrom, and R. Balachandar, Roughness effects in low-Re $\theta$ open-channel turbulent boundary layers. Experiments in Fluids, 2003. 35(4): p. 338-346.

15. Afzal, B., M.A. Faruque, and R. Balachandar, Effect of Reynolds number, near-wall perturbation and turbulence on smooth open-channel flows. Journal of Hydraulic Research, 2009. 47(1): p. 66-81.

16. Ghoma, M., K. Hussin, and S. Tait. The Experimental and Numerical Approch of Two-phase Flows by a Wall Jets on Rough Beds in Open Channel Flow. in Proceedings of the World Congress on Engineering. 2014.

17. Channelflow. Logarithmic law and Power Law velocity profile. 2015 [cited 2015 19-08-2015]; http://www.nortek.com.cn/lib/Tutorial\%20$\% 20 \mathrm{web} \% 20$ content/channel-flow/channel-flowfig1/image view fullscreen].

18. Yeh, Y. and $\bar{H}$. Cummins, Localized fluid flow measurements with an He-Ne laser spectrometer. Applied Physics Letters, 1964. 4(10): p. 176-178.

19. Nezu, I., A. Tominaga, and H. Nakagawa, Field measurements of secondary currents in straight rivers. Journal of Hydraulic Engineering, 1993. 119(5): p. 598-614.

20. Dantecdynamics. Laser Doppler Anemometer. 2015 [cited 2015 18-08-2015].

21. Liao, J.C., et al., Fish exploiting vortices decrease muscle activity. Science, 2003. 302(5650): p. 15661569.

22. Green, T., Particle image velocimetry in practice. 2009: Luleå tekniska universitet. 